\title{
Traumatic tension pneumothorax caused by Sylvester Palm frond
}

\author{
Hryhoriy Bohdanovych Zhoba*1, Wesley Blake Vanderlan² \\ ${ }^{1}$ Florida State University, United States \\ ${ }^{2}$ Department of Surgery, Uniformed Services University of the Health Sciences, United States
}

Received: December 20, 2018

DOI: $10.5430 /$ css.v5n $1 \mathrm{p} 24$
Accepted: March 11, $2019 \quad$ Online Published: April 23, 2019

URL: https://doi.org/10.5430/css.v5n1p24

\begin{abstract}
Traumatic tension pneumothoraces can result from blunt or penetrating trauma. We present a case of a 48-year-old man that was diagnosed with traumatic tension pneumothorax following anterior penetrating left hemithorax trauma from a Sylvester Palm frond thorn. Prior reports of traumatic tension pneumothoraces resulting from Sylvester Palm frond thorns were not found in the surveyed literature.
\end{abstract}

Key Words: Pneumothorax, Traumatic pneumothorax, Tension pneumothorax, Lateral chest puncture, Sylvester Palm, Chest tube, Thoracostomy

\section{INTRODUCTION}

Traumatic tension pneumothorax (Ptx) may result from blunt or penetrating trauma. Increasing intrathoracic pressure resulting from a traumatic tension pneumothorax may lead to progressive respiratory inefficiency, cardiovascular collapse, and death. ${ }^{[1]}$ Tension Ptx requires immediate decompression. Temporary decompression may be provided with needle thoracotomy. ${ }^{[2]}$ Chest tube thoracotomy provides definitive decompression and may be the initial choice for decompression or as a mandatory procedure following needle thoracotomy. ${ }^{[2]}$ Successful needle thoracostomy favors a 14 gauge/4.5-centimeter angiocatheter. ${ }^{[3]}$ Choice of chest tube size may vary with clinical judgment. Chest tube sizes for traumatic tension pneumothoraces typically range from 28 French to 40 French. ${ }^{[4]}$

\section{CASE REPORT}

The patient was a 48-year-old African American male presenting to a Level II State Verified Trauma center with acute complaints of persistent and progressive left-sided chest pain following penetrating anterior midclavicular chest wall trauma from a Sylvester Palm frond thorn (see Figures $1 \&$ 2). Shortness of Breath, hemoptysis, radiation of chest pain, nausea, vomiting, near syncope, syncope and abdominal pain were all denied. Vital signs on admission included a heart rate of 76 beats per minute, respiratory rate of 18 breaths per minute, blood pressure of $168 / 108 \mathrm{mmHg}$, a temperature of 96.6 degrees Fahrenheit, and a pulse oximetry indicating 98\% saturation on room air. A physical exam revealed a welldeveloped, well-nourished adult African American male in mild to moderate discomfort from pain which he rated at $7 / 10$. The physical exam was otherwise normal except for decreased breath sounds overlying the left hemithorax and a small puncture wound superior to the left areola. No subcutaneous emphysema was appreciated. Portable Chest X-ray was ordered immediately by the evaluating board-certified emergency medicine physician. Tension pneumothorax was revealed, and trauma surgical consultation was requested (see

*Correspondence: Hryhoriy Bohdanovych Zhoba; Email: greg.zhoba@ hotmail.com; Address: Florida State University, United States. 
Figure 3). Decompression was achieved with a 22 French left chest tube thoracotomy placed in the left mid-axillary 5th intercostal space (see Figure 4). The patient was then admitted to the trauma service where he recovered with complications. The chest tube was discontinued on hospital day \#4 and the patient was discharged to home on hospital day \#5. Follow up evaluation in clinic demonstrated complete resolution of symptoms and no evidence of recurrent pneumothorax.

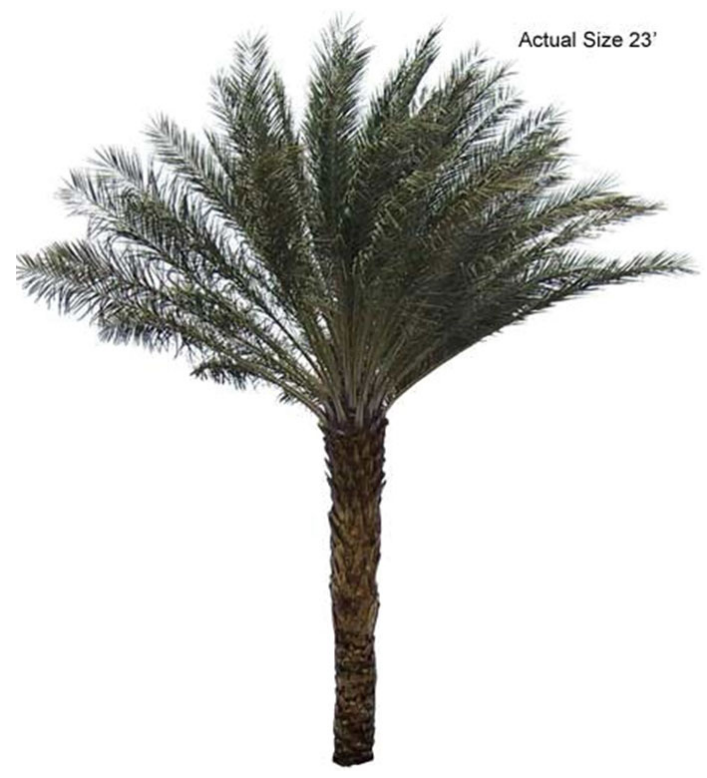

Figure 1. Sylvester Palm Tree

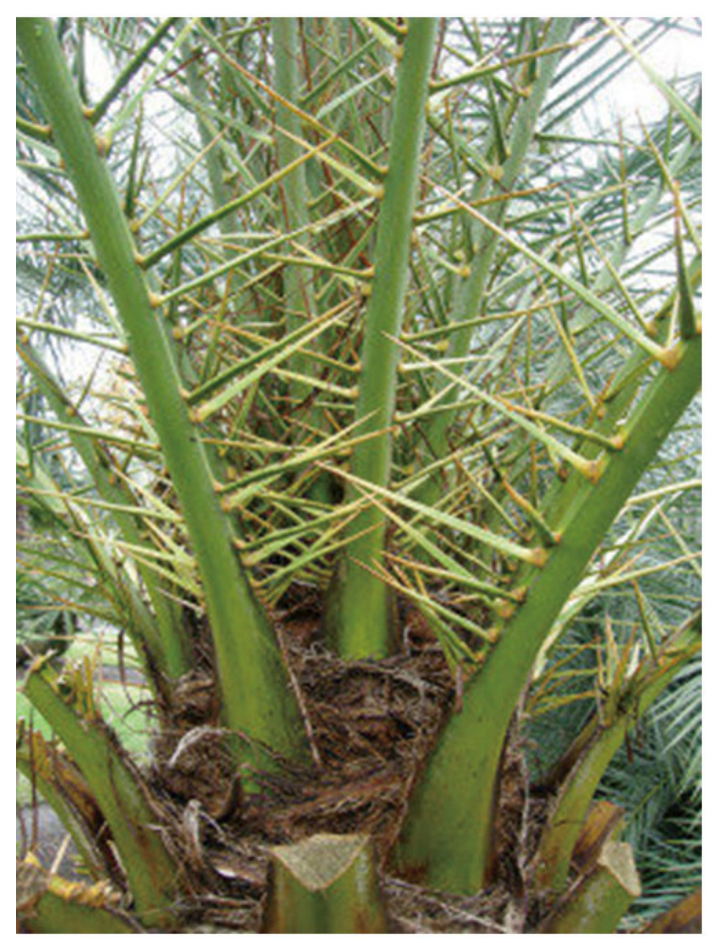

Figure 2. Sylvester Palm Fronds with Thorns

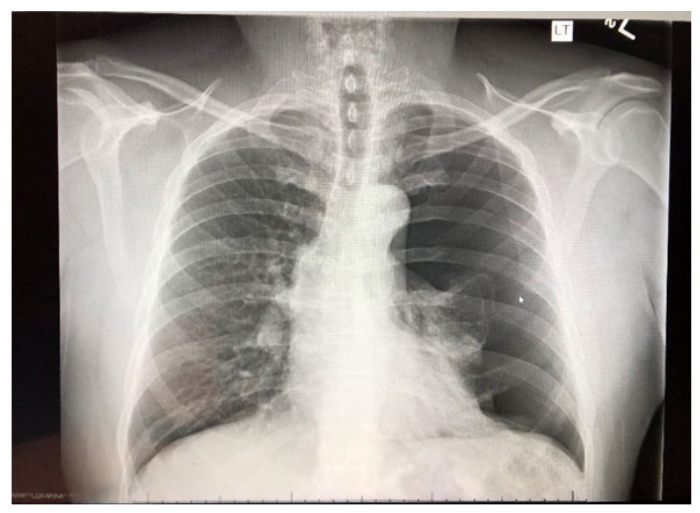

Figure 3. Left Tension Pneumothorax

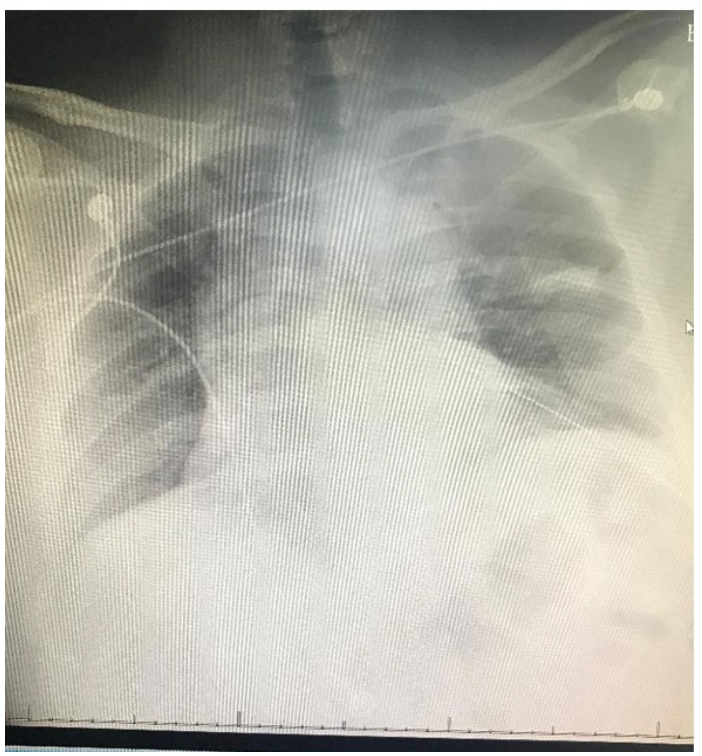

Figure 4. Left Chest Tube Thoracotomy

\section{Discussion}

The reported patient presented with a penetrating injury to the left hemithorax from a Sylvester Palm tree frond. No prior reports of tension pneumothorax occurring with penetrating injury to the chest by thorns were observed in the surveyed literature. To the casual observer, the probability of a major life-threatening injury secondary to a palm frond thorn may seem remote at best. Presenting symptoms in the referenced patient included persistent and progressive ipsilateral chest pain associated with a clinical exam finding of decreased ipsilateral breath sounds. Clinical acumen lead to a definitive diagnosis. Needle thoracotomy was deferred since the patient was hemodynamically stable and without evidence of respiratory distress. Radiographic imaging revealed no evidence of hemothorax leading to the selection of a 22 French chest tube. ${ }^{[5]}$

\section{CONFLicts OF InTEREST Disclosure}

The authors declare they have no conflicts of interest. 


\section{REFERENCES}

[1] Sharma A, Jindal P. Principles of diagnosis and management of traumatic pneumothorax. J Emerg Trauma Shock. 2008; 1(1): 34-41 PMid:19561940. https://doi .org/10.4103/0974-2700.4178 9

[2] ATLS Subcommittee, American College of Surgeons' Committee on Trauma, International ATLS working group: Advanced Trauma Life Support (ATLS): 9th ed. J Trauma Acute Care Surg. 2013; 74: 1363-1366. https://doi .org/10.1097/01586154-201305000 $-00026$

[3] Rottenstreich M, Fay S, Pendler S, et al. Needle Thoracotomy in Trauma. Military Medicine. 2015; 180(12): 1211-1213
PMid:26633663. https://doi.org/10.7205/MILMED-D-14-0 0730

[4] Inaba K, Lustenberger T, Recinos G, et al. Does size matter? A prospective analysis of 28 - 32 versus 36 - 40 French chest tube size in trauma. J Trauma Acute Care Surg. 2012; 72(2): 422-427. PMid:22327984. https://doi.org/10.1097/TA.0b013e31824 52444

[5] Baumann MH. What size chest tube? What drainage system is ideal? And other chest tube management questions. Curt Opin Pulm Med. 2003; 9(4): 276-281. https://doi.org/10.1097/00063198-2 00307000-00006 